\title{
Cianose e metahemoglobinemia associada à deficiência de NADH- metahemoglobina redutase em um cão sob anestesia
}

\author{
Cyanosis and methahemoglobinaemia associated with NADH- \\ methahemoglobin reductase deficiency in a dog under anesthesia
}

\author{
Aury Nunes Moraes, ${ }^{*}$ Fabíola Niederauer Flores, ${ }^{\star}$ Sabrina Geni Tavares, ${ }^{*}$; Jonhn H. Lumsden, ${ }^{* *}$ \\ David L. Holmberg, ${ }^{* *}$ Andrew J. Mackin ${ }^{\star *}$
}

\begin{abstract}
Resumo
Este estudo relata a ocorrência de cianose em um cão sob anestesia geral. O paciente não apresentava sinal de doença cardíaca ou respiratória, não havia possibilidade de ingestão acidental de agentes oxidantes, resultando então na suspeita de metahemoglobinemia associada à deficiência de NADH-metahemoglobina redutase. Sendo esta confirmada após teste sugestivo e confirmação laboratorial por teste específico.
\end{abstract}

Palavras-chave: anestesia, cianose, metahemoglobinemia, cão.

\begin{abstract}
This study reports the occurrence of cyanosis in a dog under general anesthesia. The patient didn't present any sign of heart or respiratory disease, the accidental ingestion of oxidizers agents wasn't possible. Therefore resulting the suspicion of metahemoglobinemia associated to the deficiency of $\mathrm{NADH}$-metahemoglobina redutase. This was confirmed after suggestive test and laboratorial specific test.
\end{abstract}

Keywords: anesthesia, cyanosis, methahemoglobinaemia, dog.

Um cão da raça Esquimó Americano Toy de quatro anos, 3,4 $\mathrm{kg}$, fêmea, foi apresentado ao Ontario Veterinary College, no Canadá, com histórico de Dermatite Perivulvar Crônica sem resposta a medicação. Foi realizada biópsia de pele para exame histopatológico, que confirmou o diagnóstico de dermatite perivulvar superficial compatível com Intertrigo da dobra vulvar.

$O$ animal foi submetido à cirurgia de Episioplastia para correção da anormalidade. A única alteração significativa encontrada no exame clínico foi obesidade moderada e imaturidade vulvar. Hemograma completo, perfil bioquímico e urinálise estavam normais. O protocolo anestésico utilizado foi acepromazina $0,05 \mathrm{mg} \cdot \mathrm{kg}^{-1}$ e oximorfona $0,05 \mathrm{mg} \cdot \mathrm{kg}^{-1}$, por via intramuscular, indução com tiopental $2 \% 10 \mathrm{mg}^{\mathrm{kg}}{ }^{-1}$ por via intravenosa seguida da intubação orotraqueal e manutenção com halotano e oxigênio em circuito de Bain. Foi administrada oximorfona $0,05 \mathrm{mg} \cdot \mathrm{kg}^{-1}$ diluída em solução salina $0,2 \mathrm{ml} / \mathrm{kg}$ para analgesia epidural, após a colocação do animal na manutenção da anestesia. Dez minutos após o início da anestesia o paciente mostrou sinais significantes de cianose, imediatamente foi avaliada a profundidade anestésica pela ausência de reflexos, formato da pupila e monitoração da pressão arterial não invasiva sistólica, média e diastólica do paciente, apresentando valores de 100, 80 e $60 \mathrm{mmHg}$, respectivamente, parâmetros todos demonstrativos que a anestesia não estava excessiva. As vias aéreas foram inspecionadas, na procura de alguma obstrução da sonda orotraqueal, não havendo nenhuma anormalidade. Após avaliação do paciente, uma inspeção completa do aparelho de anestesia foi realizada o qual não apresentou alteração de vazamento no circuito anestésico. O passo seguinte foi realizar coleta de amostra de sangue da artéria podal dorsal para gasometria (Amostra 1) - Tabela 1, apresentando valores normais. Por apresentar um padrão respiratório irregular e sinais de anestesia superficial, o paciente foi colocado em ventilação mecânica, com uma freqüência respiratória de 12 movimentos/minuto, volume corrente de $12 \mathrm{ml} . \mathrm{kg}$ e pressão expiratória final de $15 \mathrm{~cm}$ de $\mathrm{H}_{2} \mathrm{O}$, reduzindose a concentração anestésica com o ínicio da ventilação. Após

* Centro de Ciências Agroveterinário - Universidade do Estado de Santa Catarina - UDESC, Av: Luiz de Camões - 1020, 88520-000, Lages, SC. E-mail: a2anm@cav.Udesc.br

** Ontario Veterinary College - University of Guelph, Guelph, Ontário N1G 2W7. 
20 minutos da primeira coleta foi colhida nova amostra de sangue arterial (Amostra 2) - Tabela 1. apresentando significante decréscimo na $\mathrm{PCO}_{2}$. No entanto o paciente tinha altos valores de $\mathrm{PaO}_{2}$ com persistência da cianose no decorrer da cirurgia. Durante a recuperação foi colhida uma terceira amostra e os valores eram normais (Amostra 3) - Tabela 1. Com todas as amostras sanguíneas não foi possível caracterizar qual seria o problema do paciente. A possibilidade de metahemoglobinemia foi a suspeita clínica aceita.

Um teste simples pode ser feito para diferenciar cianose por metahemoglobinemia de outras causas. A coloração escura do sangue de pacientes com desordens cardíacas ou pulmonares rapidamente adquire coloração mais clara quando agitada em contato com o ar.

Casos de metahemoglobinemia, essa coloração escura persiste mesmo em contato com o ar (Kumar et al., 1999, Kushner e Mackin, 1999).

No retorno para retirada de pontos foi colhido sangue venoso para diagnóstico presuntivo, uma vez que o animal não apresentava nenhum sinal de cianose. Amostras de dois animais controles foram colhidas para comparação. O sangue colhido do paciente tinha aspecto escuro. Gotas foram expostas ao ar num papel filtro branco e agitadas por 15 minutos, quando a amostra do paciente foi comparada com os controles permanecia com a coloração marrom. A persistência de coloração marrom na amostra do paciente em questão era sugestivo da presença excessiva de metahemoglobina ou deficiência de NADH-metahemoglobina redutase. Neste caso um teste mais específico de espectrofotometria foi realizado, confirmando a suspeita.

As amostras foram então enviadas à Universidade da Flórida para ensaios de metahemoglobina e metahemoglobina redutase por espectrofotômetro (Tabela 2). A metahemoglobina estava aumentada no sangue do paciente, assim como havia baixa atividade de metahemoglobina redutase quando submetida a $\mathrm{NADH}$-ferrocianida redutase a $30^{\circ} \mathrm{C}$.

O aumento na formação de metahemoglobina pode ser devido à administração de agentes oxidantes como, nitratos, nitritos, fenacetinas e benzocaína (Brunato, Garziera e Bruguglio, 2003; Kushner e Mackin, 1999). A deficiência congênita de NADH-
Tabela 1: Amostras de sangue arterial colhida da artéria podal dorsal durante o procedimento

\begin{tabular}{|c|c|c|c|}
\hline & $\begin{array}{l}\text { Amostra } 1 \\
\text { (10 minutos } \\
\text { após início } \\
\text { da cirurgia) }\end{array}$ & $\begin{array}{c}\text { Amostra } 2 \\
(20 \text { minutos } \\
\text { após amostra 1) }\end{array}$ & $\begin{array}{c}\text { Amostra } 3 \\
\text { (recuperação } \\
\text { anestésica) }\end{array}$ \\
\hline $\mathrm{pH}$ & 7,392 & 7,457 & 7,392 \\
\hline $\mathrm{PCO}_{2}$ & 37,9 & 28,7 & 34.6 \\
\hline $\mathrm{PO}_{2}$ & 407,8 & 586,3 & 103,4 \\
\hline $\mathrm{HCO}_{3}$ & 22,8 & 20,2 & 20,8 \\
\hline EB & $-1,4$ & $-2,2$ & $-3,0$ \\
\hline $\mathrm{SatO}_{2}$ & $99,8(\%)$ & $99,9(\%)$ & $99,8(\%)$ \\
\hline
\end{tabular}

Valores mensurados na Universidade da Flórida por Dr. J.W. Harvey.

Tabela 2: Valores de metahemoglobina e metahemoglobina redutase em eritrócitos de cão da raça Esquimó Americano Toy e dois animais controle

\begin{tabular}{lcc}
\hline & MetHb (\%) & $\begin{array}{c}\text { MetHb Redutase } \\
(\mathrm{IU} / \mathrm{g})^{\mathbf{a}}\end{array}$ \\
\hline Paciente (186401) & 17,3 & 8,4 \\
Controle A & 1,1 & 22,0 \\
Controle B & 1,0 & 25,6 \\
Normal & $<1,2$ & $22.5 \pm 2,6$ \\
\hline
\end{tabular}

metahemoglobina redutase já foi descrita em cães e gatos (Harvey, Dahl e High, 1994). Os sinais clínicos no caso da deficiência congênita incluem cianose, intolerância a exercício e dispnéia; porém, alguns animais podem não desenvolver tais sinais clínicos (Kushner e Mackin, 1999).

$\mathrm{Na}$ anamnese, os proprietários relataram que não havia possibilidade de exposição a qualquer desses agentes oxidantes, não havia histórico nem mesmo alterações no eletrocardiograma e na radiografia de tórax indicativos de patologias cardíacas ou respiratórias.

Apesar da cianose, o cão deste relato não apresentava outros sinais clínicos. Assim, esta alteração apresentada teve como causa metahemoglobinemia associada à deficiência de $\mathrm{NADH}$-metahemoglobina redutase.

\section{Agradecimentos}

Os autores agradecem ao Dr. J.W. Harvey pelas análises realizadas.

\section{Referências}

BRUNATO, F.; GARZIERA, M. G.; BRIGUGLIO, E. A severe methaemoglobinaemia induced by nitrates: a case report. Eur J Emerg Med., v. 10, n. 4, p. 326-330, 2003.

HARVEY, J. W.; DAHL, M.; HIGH, M. E. Methemoglobin reductase deficiency in a cat. J Am Vet Med Assoc., v. 205, p. 1290-1291, 1994.
KUMAR, U. et al. Central cyanosis in a young man. Postgrad Med J., v. 75, p. 693-696, 1999.

KUSHNER L. I.; MACKIN, A. J. Anesthesia case of the month Cyanosis in a dog during anesthesia. J Am Vet Med Assoc., v. 214, n. 7, p. 1007-1009, 1999. 